\title{
Going 100\% On-line with Language Courses: Possible?
}

\author{
Kristina Mullamaa \\ Language Centre, University of Tartu, Estonia \\ Email: kristina.mullamaa@ut.ee
}

\begin{abstract}
The word around us is changing constantly and it has an enormous impact on the learning environment and students' learning styles. Sometimes, technological change is said to be the only constant in our life. Thus, applying modern IT solutions in teaching and learning has become a part and parcel of an increasing number of learning programmes. In language teaching, however, resorting to ICT solutions is sometimes considered to be controversial. This article explores some positive aspects of using ICT that have been acknowledged and stimulating both for students and the teacher. We share our experience in using the Blackboard e-learning environment for teaching genese language courses at different levels and different languages (English and Swedish), and English for Specific Purposes (ESP). We have experienced that the webbased environment can be successfully used for supporting student-centred learning and increasing student motivation. It is also a flexible environment for developing individualisation and enabling cooperation with the students. These topic areas will be the main focus of our paper. By way of introduction we shall analyse different past and current courses where the web-based environment has been used as a support for in-class teaching. We will view different ways of motivating students and engaging them in the learning process. We will then move on to discuss the experience of going $100 \%$ on-line with the language courses and analyse the feedback from students questionnaires and self-analysis reports, as well as the results of our participant observation of the process, with a special focus on examining the possibilities for supporting and encouraging student-centred learning and increasing student responsibility in their learning process.
\end{abstract}

Index Terms-e-learning, ICT, language learning/ teaching, student centred learning, student responsibility, motivation

\section{INTRODUCTION}

E-learning is an increasingly popular area of modern education. However, when applied in language learning, the attitudes towards going on-line may differ. Many educationalists appreciate its values and see it as a wonderful resource for making the learning process more diverse and attractive. Others have an inclination to criticise the limits of elearning. Comparing e-based language learning to traditional eye-to-eye classes does not always show the former in the more favourable light. Especially so when we believe that in language learning, speaking and communication are crucial.

Yet, attitudes can be changed and attractive ways for enticing university lecturers to get started with e-learning have been developed in different parts of the world. In Estonia, at the University of Tartu, e-learning sessions called "coffee with e-learning" started to be arranged for teachers. The idea came from Scandinavia. These training sessions, taking place once a month during the lunch break of the last working day in the week, offered tempting delicacies to coffee. And in an easily accessible and pleasant way the "e-lunches" introduced us state-of-the-art knowledge about e-learning. The ICT solutions were taught by the IT-support staff who also became the tutors of the teaching staff during building and carrying out the e-courses. Thus, the scene was set for experimenting with a new learning and teaching environment.

In language teaching, the educational and tutoring support available can be used in creating the e-learning environments for teaching general language courses in different languages at different levels; for learning terminology, and ESP (English for Specific Purposes) in different fields of specialisation. Designing and building up the courses was supported by funding from the EU.

Our experience of using e-learning as a support to our eye-to-eye classes has proved to be positive and stimulating. ICT supports student-centred learning and enables us to increase student responsibility, at the same time having personalised and prompt teacher feedback. Going $100 \%$ online was nevertheless a rather different experience and judged by the pilot version of the course it seemed to put to the test rather different capacities, both concerning the teacher and the students. In the article below, we would like to share some of these experiences.

\section{STUDENT Motivation AND E-LEARNING}

\section{A. Motivation}

Web-based learning necessarily implies a great amount of student responsibility and focusing. It also applies motivation, which is essential for a learning process to take place. What is motivation? 
In general, definitions of motivation in education emphasise the eagerness, willingness and readiness of people to try, achieve or acquire something. As Rob Dean (2010) points out, for motivation to occur, for the students there needs to be: an interest in the topic

the will to understand and do more

the feeling that one can understand and can do more

Motivation is crucial, as without it students would not consider participating in a course in the first place. In theories of motivation, motivation is often divided into extrinsic and intrinsic motivation. Theobald (2006: 1) points out that for some students it is essential to resort to extrinsic tools to increase their motivation. This tends to be the factor behind most of the justification behind teacher-centred teaching. Intrinsic motivation, however, has been seen as "the ultimate goal of educators for their students" (ibid.). When we speak about student-centred teaching, we in fact imply that students should have the wish (and skills!) to be independent learners and to take responsibility of their learning process. How can we make students reach this? Intrinsic motivation is often attributed to finding a value in what students do. Theobald (2006: 1) holds:

"Helping students find value in learning through the implementation of various instructional strategies and multiple alternative and authentic forms of assessments, while maintaining high standards of student performance in an environment which encourages students to do their best work by effective, nurturing teachers, will help increase the motivational levels of all students".

Dörnyei and Otto (1998:65) give us a definition of L2 (second/ foreign language) motivation:

"In a general sense, motivation can be defined as the dynamically changing cumulative arousal in a person that initiates, directs, coordinates, amplifies, terminates, and evaluates the cognitive and motor processes whereby initial wishes and desires are selected, prioritised, operationalised and (successfully or unsuccessfully) acted out".

Hasanbegovic (2005) has reviewed a study on the impact of intrinsic motivation on e-learning in authentic computer tasks by Martens et al. 2004. The study allows her to conclude:

"In line with the motivation theory of Ryan and Deci it is predicted and evidenced that intrinsically motivated students do more in a fixed time period as a result of their higher effort and persistence and will do different things in computer environments that allow for this liberty of choice (Hasanbegovic 2005)".

A well-balanced ITC environment enables students to feel intrinsic motivation and to stay motivated throughout the learning process. ICT can be harnessed in the interest of developing modern principles of learning and language acquisition concerning motivation. The criteria mentioned above can be met in e-tasks that are programmed to automatically increase the level of difficulty, to adapt to the student's language level or to repeat areas where the student has made mistakes during previous visits to the electronic environment. In the description above, also the needs for individualisation are met. And obviously, and high-quality e-learning environment meets the needs for a certain amount of playfulness and interaction.

Thus, some of the most important aspects of learning - individualisation, interaction and student motivation, often considered paramount in modern education theories, are necessarily a part of the process in ICT. Motivation, individualisation, learning in context and the activation of the learner - all buzzwords in modern education - are often a part and a parcel of a successful ICT support.

\section{B. Modern Discourse in Professional Roles: Increasing Learner Responsibility and Changing Teachers' Roles}

An equally important aspect is learner responsibility - the students' capacity to envision and pursue their goals. A modern student, especially at the university level, must know why and what s/he needs to study, and to be able to design and stick to their personal study plan. Wilson (1981: 61) points out that student development through the university years can be seen as follows:

"One view is that student growth occurs through an invariant sequence of stages or levels in which progress from stage to stage implies a restructuring and reorganisation of what went before. 'Higher' stages are qualitatively different from 'lower' stages in terms of the way the individual thinks, feels or acts. Another influential view is that student development is to be seen in terms of mastery of a series of developmental 'tasks' which involve the individual's maturation in the different aspects of intellect, emotions and social relationships".

Today, the role of the teacher is that of an advisor, an expert in the field whose task is to support the students' development (cf. Mullamaa 2009). This is much more creative and much more challenging than the more traditional "design and control the study process" concepts. Dörnyei (2001:35) points out:

".../ teachers are powerful motivational socialisers. Being the officially designated leaders within the classroom, they embody group conscience, symbolise the group's unity and identity, and serve as a model or a reference/ standard. They also function as an 'emotional amplifier' of the group whose appeals and examples are critical for mobilising the group /.../. Simply speaking, to lead means to direct and energise, that is, to motivate".

In education, as elsewhere, increased cooperation and neglecting the earlier rigid borderlines, is becoming more and more common practice. Day and Sachs (2004: 7) indicate: "The core democratic professionalism is an emphasis on collaborative, cooperative action between teachers and other educational stakeholders".

Karm and Remmik (2010) stress the importance of university teacher's routes of development. They (ibid.) note that only if a teacher has understood the underlying importance of her teaching viz-a-viz the teaching skills, the development of one's field of specialisation, and personal development of students, does the need for further education occur. And 
we believe, it is often in the course of further education and mentoring that further processes of self-monitoring, improving one's teaching and conceptualising one's role occur.

Kiggins and Cambourne (2007: 368-379) emphasise the importance of a "triadic partnership" (ibid. 374) from the very beginning of training of young teachers. Kiggins and Cambourne (ibid.) stress: “/.../ trust becomes a required element in the knowledge building process, and if friendship and trust are not present among the student cohort, this process is unlikely to occur".

Modern education theories also emphasise the importance of neglecting the former rigid models of seeing the students' minds as "an empty space" to be filled with information. Rather, students' interest for learning, and their creativity should be developed with the help of encouraging and creative teachers. Thus, the challenges teachers are facing today are significantly more serious and demanding. Indeed, the amount of responsibilities that today go along with the teaching profession per se has increased significantly. As Day and Sachs (2004: 7) point out:

"It suggests that the teacher has a wider responsibility than the single classroom and includes contributing to the school, the system, other students, the wider community and collective responsibilities of teachers themselves as a group and the broader profession /.../".

At the school level, the code of ethics for teachers was developed in 2004 in Estonia. Further education training programmes are carried out. However, traditional, teacher-centred and rather authoritarian teaching stiles are regrettably still favoured by some representatives of the teaching staff as well as parents. The formulation of the code of ethics for university teachers is currently in progress. Discussions in the media on the issue are strongly encouraged. Further education programmes for modern further education of university teachers are in progress and they are attended by an increasing number of university teachers. There are also different mentoring projects taking place. In all these endeavours the issues of ethics, the role boundaries, as well as the contribution to society, are clearly present. On the positive side, we see an active discussion on the core issues in the media, and an active appeal for modern and childand student-centred approaches in training and teachers' learning communities.

\section{The Possibilities for ICT: Individualisation, Activating the Students, and Learning Concepts in Situated Meanings}

As Normak (2010) points out, the environment in which learners develop is crucial for success. Normak (ibid.) analyses sources of research on early child development and the development of logical thinking, reaching the conclusion that a safe learning environment from the very early years on, and a certain playfulness are essential for developing thinking and becoming successful learners and members of society. E-learning has plentiful possibilities for catering for such needs also in the later stages of learning. The possibilities for ICT include individualisation, activating the students and learning concepts in situated meanings.

The importance of learning of concepts in situated meanings is stressed by Gee (2009: 15). Gee (ibid.) points out that students need to acquire and try out the contents of concepts in situations that teach and test their real meaning. Only then true learning takes place. Without that, students may be able to complete seemingly perfect "pen and paper" tests. However, at closer testing, they prove not to be able to solve real problems (cf. Gardner 1991, in Gee 2009: 15).

We suggest that ICT and web-based learning solutions offer the learners the possibilities for making the learning process more interesting and challenging. Some of the capacities here are attractive and enthusing, even similar to what has been pointed out as the educational reserve of video games. J P Gee suggests (2009) that the principles these follow often relate to the principles of encouraging active learning. Out of the capacities that Gee relates to positive learning techniques in video-games (Gee 2009: 22), we associate with ICT the following: interactivity, adaptability, a gradual build-up of the level of difficulty, and following the principle of the "cycle of expertise". Also, the modernity of the medium and its parallels to the developments in virtually all other spheres of human life, where the digital revolution reaches from citizen journalism to museum pedagogy (cf. Gottlieb 2009: 26-37), help to make it attractive.

A recent SRI International for the Department of Education in Estonia (http://www.ed.gov/rschstat/eval/tech/evidence-based-practices/finalreport.pdf) demonstrates that the learning results that have been reached by using ICT solutions are more profound than the learning results achieved through using traditional learning methods:

"On average, students in online learning conditions performed better than those receiving face-to-face instruction. Over the 12-year span, the report found 99 studies in which there were quantitative comparisons of online and classroom performance for the same courses. The analysis for the Department of Education found that, on average, students doing some or all of the course online would rank in the 59th percentile in tested performance, compared with the average classroom student scoring in the 50th percentile".

As pointed out above, research has also shown that in the $21^{\text {st }}$ century the focus in training future capable members of society should be on not only forwarding information and accumulating knowledge, but also on training working in groups, adaptation to changes, and applying technological change. Below, let us take a look at how this can be done, using ICT using our practical experience with language teaching as an illustration for this.

\section{THE EXPERIENCE OF USING ICT IN BLENDED LEARNING}

In our experience, ICT has proved to be a good environment for teaching general language courses, as well as for teaching/ learning terminology and ESP (English for Specific Purposes). The courses have been conducted as a 
complementary to ordinary classroom teaching, i.e. the web-based courses usually run parallel to the face-to-face seminars. Their primary goal is to support what has been learned in the classroom and thus they mainly include exercises on texts/ grammar covered in the classroom.

In addition to learning and acquiring new vocabulary in English and Swedish the courses aim at helping students to form their personal opinion and being able to express it on issues topical in one's field of specialisation, as well as topics of general interest (links to topical articles \& hot debates both in Estonia \& abroad, web-links, multimedia resources).

Exercises designed as an extension to activities carried out in the classroom support the acquisition of vocabulary, forming one's personal opinion, and being able to express it on topical issues. It enables students to understand their area of specialisation and many other important issues in a wider context and to put it into a perspective that stretches beyond their university, country, and continent.

The web-based solutions also offer good possibilities for carrying out eye-to-eye lessons in the computer classroom. The ICT solutions can be used as a support for different classroom activities, e.g. the group-work and pair-work assignments in class, but also for follow-up independent work on classroom activities for students with a different learning style, or as preparatory work. The goal in all these instances is to encourage student-centred learning and the principles of individualisation (different interests/ levels/ needs). E-learning as a support for learning in the classroom enables us to make the study process more flexible and to better take into consideration the needs of different students. The students are active and "a part of the process".

For example, the Web-based environment can host different multimedia possibilities for developing speaking skills. It may be done in many different ways.

One of the favourites of our students has been the jig-saw pair-work activities that involve "voice-over" exercises on video-clips. This entails watching different video-clips, answering the different questions to both students that become in essence a short summary of the clip they have seen, and finally, replaying the respective videos with one's partner with the voice on mute, the respective student in charge of a certain video providing a voice-over. If you find an informative and interesting clip on a subject area you are currently working on with advanced students or an ESP group, such an activity can provide students with the latest information, buzz-words and key expressions on the subject area, at the same time offering them a fair amount of challenge.

Another popular activity is finding additional information on the texts, phenomena or people spoken about in our articles or student presentations. We often build this up as a group-work activity. And while in ordinary class-room settings the feedback information from the buzz groups remains preserved in our memory, or at paper boards, the ICT learning environment enables students to access their final feedback posted there also later during the course, wherever they are - at home or in Hawaii. Also, the current licences allow us to keep the courses open for participants for at least half a year after attending the course, thus offering perfect possibilities for a longitudinal learning process, and revisiting the materials beyond the official end of the learning cycle. This possibility, coupled with the attention of students from parallel groups and "future generations", is most stimulating, and even encourages them to have an unofficial friendly competition on whose report or power-point presentation looks the best.

To sum up, ICT as a support for ordinary class-room teaching, and as a part of it, has the obvious benefits of easy access whenever and wherever you wish it, dematerialisation (less paper - more trees), enabling us to use modern methodologies, individualisation, possibilities to develop contacts beyond our university, state, continent ("broadening the horizons"; "real English", or other foreign language).

Students have an overview of topical issues, their context and background, easy access for quickly finding inspiration for (continuing) the conversation, developing the skills for finding the right information, analyse, present and discuss it, developing the skills for using the e-environment and new technologies, developing responsibility for the learning process, forming one's own opinion and learning to (dare to!) express it.

\section{GOING 100\% ONLINE: DESCRIPTION OF A PILOT COURSE}

\section{A. Optional Eye-to-eye Meetings to Back-up the Course}

Despite the positive experience in blended learning, going $100 \%$ posed a different challenge. To safeguard against any possible problems we decided to give students an option of discussing the course eye-to-eye with the teacher at three instances: 1 . before the course; 2 in the middle of the course; and, 3 . at the end of the course.

The introductory meeting took place prior to the course. The goal was to avoid any possible problems that might be incurred by not knowing the specific e-learning environment (Blackboard). To enable students to try everything handson, they were invited to this special introductory meeting in the computer lab.

In addition to a brief introduction to the course, students had the possibility to try out navigating the course. The teacher was around to help them and answer possible questions, including support with creating the initial passwords and user names. This set-up also enabled us to ask students about their goals for the course and wishes as concerning the tasks, topics, etc. We even tried working on the first Module altogether to see how to navigate the course, and for the teacher to discover where the possible difficulties might be for the users. Reading out some parts of the texts enabled the students and teacher to see if their language level was adequate. 
The discussion session enabled students to meet each other in smaller groups, and to get at least some idea of what kind of a person you are communicating with when meeting each name. Thus, last but not least, this special eye-to-eye meeting made it possible for the students and teacher to get to know each other, and negotiate the goals and specifics of the course before continuing $100 \%$ on-line.

The meeting was not obligatory, but 12 of the 20 registered participants had chosen to attend. In retrospect we can say that such an initial meeting is definitely to be recommended, as getting acquainted with an e-learning environment one has never seen before was made so much easier for students when they could have instant help and their questions answered immediately. The majority of students who opted not to participate were already familiar with the Blackboard e-learning environment, and thus there were no major problems relating to the ability to use this environment during the course.

A similar optional "live" meeting possibility was offered to students in the middle of the course, and also at the end of the course. However, it seemed that the communication in the on-line environment as well as prompt teacher feedback had by this time met their purpose, so not many students attended. At the same time, the on-line discussions were most lively and adequate - thus showing, we believe, that an efficient quick-start may prove to be enough as concerns options to eye-to-eye meetings. The long-term goal is to be just $100 \%$ on-line, reducing or eliminating the eyeto-eye meetings.

\section{B. The On-line Course: the Structure and Goals of the Course}

As on-line courses require an ability to plan and effectively manage one's time and efforts, we explicitly pointed this out already in the course description and requirements. Thus, the requirements for students to qualify to attend the course were: language level: B2/C1 according to the Common European Framework, the ability and will to work independently and in group, the ability and will to plan their time and pursue their goals, computer skills to manage the Blackboard environment.

The main goals of the course were to enable students to increase their vocabulary, to enable them to read articles and text on a variety of topics and to enable them to discuss the topics. It was pointed out that they would also be able to write a short summary of the discussions (to practise using formal English), to make a report through using video- or voice recordings (or alternatively: Power-point).

To make sure that students follow their learning programme respecting the dates, we established very clear rules. These read: "one week - one lesson; be friendly and outgoing; support your group-mates; plan your time!".

To make the course easy to navigate and follow, also the course structure was very simple. It was the following:

Introduction; eye-to-eye meeting in the computer room (optional)

Module 1-3

Test 1 (on these modules)

Module 4-6

Test 2 (on these modules)

Your presentation (a link to a video-recording OR Power-point presentation)

Feedback

For each Module there was a separate week, and we also enabled students a full week for taking the tests. A separate week was devoted to the introduction to the course. After all Modules were covered, a separate week was devoted to student self-analyses and feedback.

In evaluating student progress we used the following means:

Modules - self-tests (automatic control)

Tests - students get a mark (automatic control)

Discussions, summary of discussions, presentations - group-mates

feedback + teacher evaluation

Below, let us take a closer look at the course and analyse it in terms of student-centred learning, the possibilities and possible pit-falls e-learning and an on-line course holds.

\section{The Outcome of the Course}

In retrospect we can say that the course went very well, even much better than anticipated. Two students stopped in the second and third week of the course, respectively, explaining that the course demanded more time and attention they could afford. The rest stayed. The Modules were covered on time, the self-tests taken within the allowed time limits. Participation in discussions on each Module was rather modest in the beginning of the course, but grew more active as the course proceeded.

The minor setbacks we faced included the evergreen problem that students not always read through the course demands or course plan and send individual e-mails to the teacher asking about what to do next week. Indeed, in this case the "problem maker" was only one specific student, and the tasks and course plan were so clearly presented that there was not much to do on the teacher's part.

Another problem was faced during the first automatic test, when it appeared that a couple of automatic answers most unfortunately - included some lapsus calami. Although we were politely alerted by the students and dealt with the problem at once, it appeared that the Blackboard e-learning environment did not allow us any corrections. Thus, in one 
case the preposition "of" had unfortunately been typed in as "oif", and this couldn't be changed. Later IT support established that the Blackboard is technically designed not to allow the teacher to make changes in the test once any student in the group has already taken it (thus also revisiting your course as a mock student locks the easier possibilities for correcting possible infelicities!). The idea is to prevent malicious teachers from changing the questions once the test is in progress. I have never heard of teachers doing this before, misspellings are much more common to happen, I believe. So, no easily accessible technical solutions for these make you wish to double-check your tests next time.

As for all the other applications, these worked perfectly. It appeared that students found the texts and tasks on them very well, navigating the course skilfully. Thus, the general conclusions on the course are:

The course worked well, the time framework planned and materials to be covered seemed to be justified.

Participation in discussions was less frequent yet more deep-going than expected

Most of the participants passed the course with flying colours.D. Students' Self-analysis and Feedback to the Course

We encouraged as much student feedback as possible. The goal was to improve the course, but also to help them analyse their progress and input. It was obligatory to evaluate one's progress during the eye-to-eye meetings, and if one was not able to attend, to post a detailed self-analysis. In addition to that, upon completion of the course, all students were invited to fill in an anonymous questionnaire on the course and their progress.

Below we give a brief summary of their self-analyses and the results of their anonymous feedback questionnaires. The self-analyses were written by four students and struck the eye with very good self-evaluation skills. In general, students said they were happy with the course; some admitted they should have devoted even more time to it; quite a few added thanks and some words of appreciation to the teacher.

One student mentioned he would have wanted to have more intensive A2-B1 level grammar drills. However, this wish was incompatible with the given goals and level of the course (vocabulary enhancement for $\mathrm{C} 1 / \mathrm{C} 2$ !). We did add a link to a rich self-correcting depository of self-correcting grammar exercises. As this was the same student who continuously asked for explanation of tasks in Estonian, we also concluded that his level of language was not adequate for participation in this course(as was indeed confirmed by the poor English in his postings).

The results and statistics of the rest of the feedback are in front of you. To give our readers an overview, as well as some flavour, of how students felt about using the on-line course environment, we have chosen to quote them verbatim:

The comments on "What were the new/ interesting emotions/ ideas/ thoughts/ skills gained during the course?" were the following (verbatim copy): "I enjoyed the opportunity to express my thoughts in the text form; How to improve your vocabulary through reading interesting articles on topics you like; making reviews, more new words and new discussing methods; Understanding the main idea of a large complicated text; new thoughts after reading".

Answers to "What would I like to change in this course?" included: "The tests where (sic! KM) too easy, more new words to learn, Maybe increase number of texts offered by students, more grammar drills, self tests".

"What did I like most in this course" was identified as: "I liked the possibility to plan my time myself, The possibility to do everything on my own time, discussions, ppts and other students comments to the topics".

And the general control question "What did I like in this course? Why?/ Why not?" gave the answers: "It is similar to the question above, Improving my English from home, vocabulary part in the tests should be much longer. Topics were quite interesting, Topics that interest you are easier to read, Very useful for me were the articles".

The longer, special self-evaluations posted to the Blackboard environment or sent directly to the teacher included:

"My goal was to learn some new words, improve my English and to repeat what I had already learned previously over the last years. I mostly did meet this goal, although I am not sure how much my English improved, some parts of it definitely, for example, I learned more about discussing subjects with others and making reviews and writing comments on articles. Very useful for me were the articles, I usually don't read that much articles in English. Maybe I will start doing it now. I could read other articles not only the ones given on tasks. I liked that every task was discussed with other students and everybody were taking part of it. This course was very useful, because a big amount of work was done without going to classes, so you could decide which day you will study English”.

As the excerpts given above illustrate, students had in general a rather positive attitude towards the possibilities of elearning, and this course specifically. The possibility to be in charge of one's own study process and time was evaluated the highest.

We detect from some students' remarks a strong tendency to rely on teacher-centered teaching. We believe that it illustrates some relics from our past and the rather traditional school system. As we personally believe in studentcentered methodology, to enable students to decide on which way to choose, and to have more adequate self-directing materials, in the future a special introductory module will be devoted also to the self-analysis of the learner, selfanalysis of the learning process, and on monitoring one's achievements on a broader conceptual level.

The positive surprise moment was that according to the students the course also enticed them to read more articles in English, that it raised new thoughts and ideas in them, and that students felt their skills of extrapolating information, writing reviews and compiling power-points had developed. Also, the capacity of a number of students to analyse their achievements and course benefits in a broader conceptual framework was positive. We hope this shows that some progress on the student-centered and self-analysis based conceptual learning has been made in the student body.

The answer to the question posed in the heading of this article would thus be: Yes. Going $100 \%$ on-line with language courses is possible. It would never replace a fully-fledged communicative eye-to-eye course with student and 
teacher communication, feedback, and meetings. But it can offer possibilities for self-development, on-line discussion and progressing towards one's goals in an academic e-environment where prompt teacher feedback and on-line communication with group-mates still helps one to build a framework to one's development.

Importantly, access to on-line courses may also be the only option for students who for financial reasons need to work in parallel to their university studies, and would not be able to visit a lecture at a given time or place. Also, students who may have suffered from some health problems, or are living abroad for some period of time are able to attend and have been grateful for this opportunity. Thus, we believe, there is also a social and ethical dimension to offering such courses, and through this, a possibility for participation and inclusion for those who would otherwise miss it.

\section{THE ETHICAL DimENSION: BUILDING TRUST}

A Chinese proverb says: "teachers open the door, but you must enter by yourself." Our task is to encourage students. But it is not only the new vocabulary a good language course should give them. It is essential to consider the fact that the immediacy of the information and news reaching our students (through this new language) gives them an opportunity to be informed of and shape their opinion on important topics relating to our society and the "here and now".

We wish to remind us all that, as many renowned sociologist and researchers (cf. e.g. Cronin 2002, Pym 2005) have stressed, it is not enough to have an opinion - an educated person must express it to shape the society we live in. Indeed, much of the knowledge and ideas in the modern 2.0/3.0 Web world are related to who has the information and who has it first. And who else should be encouraged to learn to use it to the best of their capacity and following all the ethical principles than students of foreign languages, who in many ways are and become the window to/ from the world of their own society and culture.

Anatole France has said: "nine tenths of education is encouragement". There can be no encouragement without trust (cf. Kiggins and Cambourne 2007: 374 in 2.2. above). As teaching in general, so can also e-learning be organised in different ways. For some, it may be a ready-made environment created by the teacher. Such an environment is often teacher controlled, students present filled-in exercises, get marks; self-tests, "the teacher's button" with which to control the computers of students when we work together in the computer classroom. In contrast to this, we have chosen to build our courses on the principles of trust. We believe that students can manage, are (almost) grown-ups, can take responsibility, are ( to a great extent) responsible for their study process. Much depends on the teacher's authority type - whether the teacher is autonomy supporting or controlling. Dörnyei (2001a:37) points out:

"Sharing responsibility with students, offering them options and choices, letting them have a say in establishing priorities, and involving them in the decision-making process enhance student self-determination and intrinsic motivation /../"'.

It definitely takes some courage from the teacher to give free rein to a group of teenagers. You have to accept a certain amount of insecurity, as there is no way to predict how each group of students approaches their course and the ICT environment. However, in our experience, supporting student autonomy shows that there is a trust for the teacher, and an increased responsibility for the learning process. Students are innovative and creative, and accepting, and making them explicitly share responsibility for the process and outcome motivates them to come forward with fascinating and useful ideas.

In education, as elsewhere, increased cooperation and neglecting of the earlier rigid borderlines, is becoming more and more of a common practice. Such an approach also helps students to retain their motivation. Cocea and Weibelzahl (2006: 2-3) point to the connection between e-learning and the Social Cognitive Learning Theory (SCT). In their view, personalization, adaptivity, affective tutoring and collaborative learning, as well as motivation - all aspects also we have emphasized above - all help to increase student satisfaction and learning quality:

"Personalization aims to make learning more effective and satisfying by adapting to the learner's needs and preferences. Among the benefits of adapting to the learner's motivation are: enhanced motivation and involvement, empowered learners - making them more responsible and active, increased satisfaction, better quality of learning etc.

Motivation is related to affective computing /.../, because self-concepts are always charged with emotions. Thus, affective agents could be used for both assessing motivation and intervention.

SCT also fits with collaborative learning, given the social framework taken in consideration by this theory and the way learning is influenced by the social context".

Rather contrary to what is sometimes supposed of a web-based environment, the experience shows that it often joins the students in the group. Offering them the possibility to communicate in an environment "natural" for them, the webbased course, if built up in a way that enables the students to participate and open up. It also serves to join the different terms (over X-mas, during the summer vacation), different parallel groups (e.g. Group A and Group B learning the same subject), different years of students learning the same subject.

This can be supported through helping students create common databases. In our case, the different power-point presentations and on-line dictionaries created by students have been the most popular items, especially so when the data-base is built up over different study years and together with the parallel group(s). Needless to say, the profiles of friends from a parallel group, and their small roster presentations of themselves also deserve great interest by the fellow 
students. And while commonly created on-line dictionaries can prove motivating for learning (and creating!) terminology and ESP for advanced students, consider how useful even creating a small roster presentation, or reading those of others, can be for a beginner-level general language student in the first months of their learning practice/ studies.

Analysing our past and current courses we may see that the Web-based environment can help to develop the sense of belonging together. In addition to common learning activities mentioned above, this can also be done through documenting different joint activities. Different common study visits or museum visits, often especially when also documented, and shared, discussed and analysed through the Web, all give their share. Creating a feeling of belonging enables students to open up, to share more information about themselves to group-mates. The supportive experience in "real life" encourages students to share more information digitally. And also vice versa - the information presented in the virtual world makes a good foundation for developing good relations in the classroom. Such processes of merging the virtual with real life, relying for technologies to find a feeling of belonging, and rejoicing over the friends' real life presence happens all the time in many modern lives today. Allowing our students to pursue this way we allow them to communicate and develop in modes and context familiar to and inspiring for them. ICT can also help to create special "bridges" between the study periods, different study-years and student groups, helping to shape the feeling of "us".

\section{CONCLUSION}

As demonstrated in the article above, the level of values and ethics may guide teachers through choosing their medium, procedures and communication patterns with communicating with their students. Behind many of the seemingly practical choices there is a worldview based on active research and recent theoretical approaches. Many years of teaching practice and - as a teacher in different learning groups - participant observation also help to analyse and shape the processes. E-learning in language learning is possible and can be stimulating. Hopefully, anchorage in deeper theories, principles and ethics can support students in making meaningful choices.

With the development of Web 2.0 and 3.0 there are still endless opportunities for novelties, development and change. Students are becoming more and more engaged, the communication and learning are less and less teacher-centred. In these developments the role of teachers, students, and learning itself are continuously changing to offer exiting possibilities for further development. Many of these developments are to be discovered in the work process together with the students and colleagues from all over the world.

Long before the e-learning era, Plato (428 BC- 348 BC) said:

"Someday, in the distant future, our grandchildren's grandchildren will develop a new equivalent of our classrooms. They will spend many hours in front of boxes with fires glowing within. May they have the wisdom to know the difference between light and knowledge".

May we have that knowledge!

Hopefully, a student-centred approach based on individualisation, increasing the student motivation, and responsibility, can be of support on this way.

\section{REFERENCES}

[1] Cocea, M, Weibelzahl, S. (2006). Motivation - included or excluded from e-learning. Accessed October 2009. http://www.easy-hub.org/stephan/cocea-celda06.pdf.

[2] Cronin, M. (2002). The Empire Talks Back: Orality, Heteronomy and the Cultural Turn in Interpreting Studies. In F. Pöchhacker, M. Shlesinger (Eds.), The Interpreting Studies Reader. London and New York: Routledge. 393-397.

[3] Day, C., Sachs, J. (2004). Professionalism, performativity and empowerment: discourses in the politics, policies and purposes of continuing professional development. In: Day, C, Sachs, J. (Eds.), International Handbook on the Continuing Professional Development of Teachers. Open University Press. UK, Bell\& Brain Ltd, Glasgow. 3-33.

[4] Dean, R. (2010). On the Road to Success. Seminar organized by Pearson/ Longman and AS Dialoog. Tartu, Estonia, in April 2010.

[5] Dörnyei, Z. (2001a). Teaching and Researching Motivation. Pearson Education Limited. Malaysia, LSP.

[6] Dörnyei, Z. (2001b). Motivational Strategies in the Language Classroom. Cambridge University Press. UK.

[7] Dörnyei, Z, Otto, I. (1998). Motivation in action: A process model of L2 motivation. Working Papers in Applied Linguistics (London: Thames Valley University), 4: 43-69.

[8] Gardner, H. (1991). The unschooled mind. How children think and how schools should teach. New York: Basic Books.

[9] Gee, J. P. (2008). Är videospel bra vid inlärning? / Are videogames good for knowledge acquisition?/ In: Kulturens Studia Generalia. Svenska kulturfonden. Oy Nord Print. 8-23.

[10] Gottlieb, H. (2008). Digitala pedagogiska artefakter - nya verktyg för pedagoger och intendenter. /Digital artefacts - new tools for teachers and museum personnell/. In: Kulturens Studia Generalia. Svenska kulturfonden. Oy Nord Print. 25-38.

[11] Handahl, G. (2004/2007). Ethics of Teaching in Higher Education. Teacher trainer courses: Teaching in Higher Education given at Tartu University. Oslo University-Tartu University. University of Tartu, 2004-2007.

[12] Hasanbegovic, J. (2005). Review of Martens, R. L et al (2004). The impact of intrinsic motivation on e-learning in authentic computer tasks. Journal of Computer Assisted Learning, Vol. 20, pp. 368-376. Accessed October 2009. $\mathrm{http} / / / \mathrm{www}$.elearning-reviews.org/topics/pedagogy/readiness/2004-martens-et-al-impact-intrinsic-motivation-elearningauthentic-computer-tasks/.

[13] Karm, M., Remmik, M. (2010). Academics' professional development as teachers. In press. 
[14] Kiggins, J., Cambourne, B. (2007). The knowledge building community program. In: T. Townsend, R. Bates (Eds.), Handbook of Teacher Education. Globalization, Standards and Professionalism in Times of Change. Springer, printed in the Netherlands. 365-381.

[15] Mullmaa, K. (2009). Ethics in Teaching: Should We Do More? In: Humanising Language Teaching, Year 11; Issue 3; June 2009. http://www.hltmag.co.uk/jun09/sart01.htm. Accessed in April 2010.

[16] Normak, P. (2010). Mida juhtida ehk kuidas juhtida juhtimatut? / What to lead or how to lead what cannot be lead?/ Lecture presented at the e-learning conference E-learning-a serious game in Tallinn, Estonia, in April 2010.

[17] Pym, A. (2005). Action Research in Translation Studies. Paper presented at the conference New Research in Translation and Interpreting Studies, International Studies Group, Tarragona, Spain, 7.-8. October 2005.

[18] SRI International for the Department of Education in Estonia. Accessed October 2009. http://www.ed.gov/rschstat/eval/tech/evidence-based-practices/finalreport.pdf.

[19] Theobald, M. (2006). Increasing Student Motivation. Strategies for Middle and High School Teachers. Corwin Press. A SAGE Publications Company, Thousand Oaks, California.

[20] Townsend, T, Bates, R. (2007). Handbook of Teacher Education. Globalization, Standards and Professionalism in Times of Change. Springer, printed in the Netherlands.

[21] Townsend, T, Bates, R. (2007). Teacher education in a new millennium: Pressures and possibilities. In: T. Townsend, R. Bates (Eds.), Handbook of Teacher Education. Globalization, Standards and Professionalism in Times of Change. Springer, printed in the Netherlands. 3-25.

[22] Wilson, J. D. (1981). Student Learning in Higher Education. Croom Helm London. New York - Toronto.

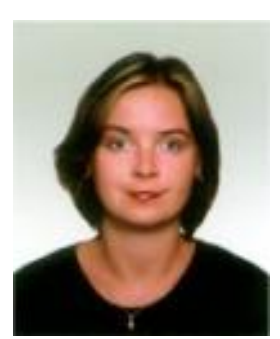

Kristina Mullamaa ( $\mathrm{PhD})$ is a lecturer of English and Swedish at the University of Tartu, Estonia. Kristina Mullamaa majored in English Philology (BA cum laude in 1996, MA cum laude in 2000) and in European Studies at Tartu University (MA in 2004). She has also studied Swedish at Uppsala and Stockholm universities in Sweden (1996, 2001), interpreting at the Institute for Translation and Interpreting (TÖI) at Stockholm University (1998). From 2003-2005 she attended the International Doctorate Programme in Translation and Intercultural Studies at Universitat Rovira i Virgili in Tarragona, Spain (DEA, 2005). In 2006 Kristina Mullamaa defended her doctoral thesis on liaison interpreters in Estonia at the University of Tartu.

The publications by her include the comprehensive Swedish-Estonian dictionary (co-author), and the comprehensive Estonian-Swedish dictionary (co-author, in press), a monograph on the role of liaison interpreters in Estonia Towards a dynamic role conception of liaison interpreters: An etnographic study of self-descriptions of practising liaison interpreters in Estonia (Tartu University Press, 2006), articles on the development on the interpreters' role, modern principles of and methods in teaching and e-learning. Kristina Mullamaa's current research interests focus on student-centred learning, the professional development of university teachers, personal and professional roles, motivation and ethics.

Kristina Mullamaa is a member of the Estonian Association of Teachers of English (EATE), the Estonian Association of Teachers of Swedish (ERKOS), member of the Teacher Training Seminars Organisers' and Language Teaching work-groups, and the head of the International Tests work group at the Language Centre of the University of Tartu. 